\title{
Inside the Virtual Test Aircraft (VIRTTAC) Benchmark Model: Simulation Architecture
}

\author{
Nicolas Fezans, Christoph Deiler \\ ${ }^{1}$ DLR - German Aerospace Center, Institute of Flight Systems, Lilienthalplatz 7, 38108 Braunschweig, Germany; \\ nicolas.fezans@dlr.de, christoph.deiler@dlr.de
}

SNE 29(1), 2019, 1-12, DOI: 10.11128/sne.29.on.10461 Received: March 21, 2019 (Selected ASIM GMMS/STS 2019 Conference Publication); Accepted: March 25, 2019 SNE - Simulation Notes Europe, ARGESIM Publisher Vienna, ISSN Print 2305-9974, Online 2306-0271, www.sne-journal.org

\begin{abstract}
This paper presents the newly introduced Virtual Test Aircraft (VIRTTAC) model for use in benchmarks for aeronautics research. This model is shared in a black-box form and the core of an open-source benchmark suite. The model needs to remain undisclosed to fulfill its purpose but the principles underlying its internal structure are described in the paper. They permit to ensure that the model equations, parameters, and states are not accessible to the user, that the model can be easily ported to other simulation environments than MATLAB/Simulink, and that it is well maintainable on the long-term.
\end{abstract}

\section{Introduction}

One of the major goals of research and innovation in aviation is to enhance the overall air traffic safety and to make traveling even more comfortable for both pilots and passengers. Novel aircraft safety and control features are normally developed for a distinct aircraft type due to e.g. a certain demand from the aircraft manufacturer or its availability for research facilities in terms of the existence of high-quality simulation models or flight testing capabilities. In the last years, numerous interesting and noticeable innovations to enhance aviation safety have been published for different aircraft types. For example, a very small study of developments in the field of aircraft flight envelope protection revealed that 12 different aircraft types or models were used in numerous publications $[1,2,3,4,5,6,7,8,9,10,11,12,13,14,15,16,17]$. Hence, comparison of all the different developments is very difficult. Furthermore, the assessment of the applicability of a published new methodology for a different type of aircraft is very difficult as normally the reader's knowledge about the underlying system is quite small. To overcome this problem and provide a common simulation model to the research community, NASA introduced in 2011 a generic aircraft simulation model called the "Transport Class Model" (TCM) derived from a sub-scale "Generic Transport Model" (GTM) simulation[18]. It is a fully functioning aircraft simulation including realistic engine and actuator behavior, sensor models and a flight control system. Although a significant number of failure scenarios were considered, computed and tested in CFD and wind tunnels [19], only a few of them were implemented in the distributed Simulink simulation model.

Moreover, the problem of comparability between various new developments is also present within the field of aircraft system identification. Various algorithms for parameter estimation and simulation model identification as well as related software tools have been developed during the last decades, but most of them were tested and verified for different aircraft. For example, Refs. [20, 21, 22, 23, 24, 25, 26, 27, 28, 29, $30,31,32,33,34,35,36,37,38]$ show results of various system identification techniques for more than 20 different aircraft types. Consequently, there is the problem to assess the quality of each methodology as there is no common base for an objective evaluation. The proposed high-quality model will be made available to all developers and will constitute a good complement to the already existing/available models.

This paper presents a new generic benchmark model that can be freely downloaded and used by the community for all kinds of investigations and in particular for defining benchmark applications to compare various approaches. This model is called VIRTTAC-Castor and is the first member of a model family called VIRTTAC, see Sections 1 and 2. The way this model works internally and the main choices made for the internal architecture of the current model implementation are 
presented in Section 3. The conditions of use and licenses are mentioned in Section 4. The foreseen applications (see Section 5) include but are not restricted to supporting the investigations related to the estimation of the reduced flight envelope, fault-tolerant aircraft flight control, or the development of enhanced system identification techniques. It is built based on the knowledge gained at DLR over several decades of flight research, including all aspects of model building based on wind tunnel and CFD data as well as from flight testing (see [39] and references therein). By distributing this benchmark model and scenarios the authors intend to share some of this knowledge with the community and to help building comparisons across techniques used by different research groups.

\section{VIRTTAC: VIRtual TesT AirCraft - Motivation and Objectives}

\subsection{Motivation}

The whole idea of creating VIRTTAC comes from the observation of the authors that in the area of flight dynamics and flight control there is a lack of commonly available, good and realistic benchmark models close to real aircraft behavior and characteristics. Most engineers and researchers are developing and/or using proprietary models for their work, but they often cannot share these models. Very often these restrictions result from the vehicles themselves and the fact that the manufacturer consider that these models might reveal some trade secrets or that they might lose some control over the investigations made based on the models of their vehicles. Within very large companies and organizations other types of issues can often be observed: dilution of responsibilities across several sub-organizations, internal dynamics, lack of incentive for long-term actions (constant changes in the intermediary management levels), often leading individuals to the conclusion that releasing some models and information is a potential risk for their career with little to no expected personal benefit.

Apart from slowing down research and innovation, this situation is also problematic in the sense that good science thrives through comparing hypotheses with observations and through independent validation of the results by different teams. Reproducibility of the results and cross-checking have been one of the corner stones in science and will remain so. Engineering-related dis- ciplines differ from more fundamental science in the sense that its actual goal is less to produce new knowledge than to create something of economical or strategical value from the current body of knowledge. Whilst new knowledge might be produced along the way, the context strongly drives engineering work towards a future return on investment. In this context, openness is mainly seen as a potential future loss of revenue and as potentially endangering the currently foreseeable revenues (e.g. through additional risks). In order to support research and science in their domains, the authors decided to build and provide VIRTTAC to the entire community.

\subsection{Objectives}

VIRTTAC is developed with two main objectives in mind.

1. Provide high-quality representative models to engineers and researchers who need some but do not have access to the kind of research infrastructure that the authors have access to.

2. Provide a wide range of benchmarks to the community with various complexity levels, including some which include as many real-world effects as possible. The objective for the most complex benchmarks is that it should never be possible to pass them successfully but fail in the real-world due to effects that could not be tested with VIRTTAC. Whilst the objective is to build complete benchmarks, the current work focuses on the development of the dynamic aircraft model at the heart of these benchmarks.

This last element "never pass the most complex benchmark if it fails in practice" directly leads to the need for representative system architectures and for modeling of all kinds of real-world effects. Information that would not be available in practice should also be hidden from the users by VIRTTAC in order to ensure that it cannot be exploited. This includes information on the internal working of the models, their exact structure, parameter values, etc. This also includes all values that are required for performing the simulations but which would not be available in practice (e.g. information for which no sensor exists or is installed/available in a real aircraft). 
"VIRTTAC users are basically aeronautical engineers who are confronted with a new aircraft.

They can flight-test the aircraft and learn how it flies, but there is still a difficulty to predict how it behaves and they cannot access physical quantities unless there is a sensor measuring them."

Most users have prior knowledge about flight mechanics/dynamics and control and should use it. The behavior of VIRTTAC will be very familiar to flight dynamics specialists, since the vehicle behaves like an aircraft. However, no equations and no aerodynamic coefficient derivatives will be made available. Precise knowledge of the aircraft can be gained by "virtually flight-testing" it (i.e. performing simulations). Knowledge can be exchanged with the rest of the community (e.g. through exchange of identified models) and is encouraged. The authors intend, aside from the website where VIRTTAC and its updates can be downloaded, to organize with the interested parties an exchange platform for the community and gather information regarding all investigations that were performed by VIRTTAC.

In the long term, the authors expect to build several models with slightly different characteristics and behaviors. For each of these models a rough description of the model will be provided. This description will include some basic description of the shape of the aircraft and its geometry and can be imagined as what a specialist would notice by looking at the aircraft. A few key technical specifications will be provided too. It is not intended for users to generate alternative data sets on the aircraft from other sources than the provided simulation model, therefore no detailed design data of any kind will be provided (no CAD geometry, structure design, etc.). The simulation is based on a nonlinear rigid-body model, which is meant to be valid for a predefined flight envelope and will include several high-lift configurations and additional effects like stall or ground effect in its final version. The aircraft briefly described in the present paper is the first of the VIRTTAC family. As it will receive some siblings, a simple naming nomenclature is introduced.

\subsection{The VIRTTAC Family: Naming Conventions}

VIRTTAC is meant to become a family composed of several models. The idea of using a naming nomenclature for the whole VIRTTAC family has been considered and rejected, at least for now, due to the diffi- culty of ensuring that this nomenclature will be precise enough to differentiate the models that would be integrated in the future and also stable over time, such that the references made to one or the other model stay valid over extended periods of time.

As the number of models and variants expected to be developed and shared within the community will remain relatively low (most likely below 15), it was decided to give names to these models and to maintain a directory with the corresponding information for each of them. The individual names will be chosen such that:

1. They can be relatively easily pronounced by a wide range of speakers and easily distinguished even if pronounced by a non-native speaker.

2. They can be easily found with a search engine. For this a web search using both "VIRTTAC" and the name of the configuration should lead only or mostly to documents related to that aircraft model, for instance past publications using this model.

Whilst the authors might chose other types of names in the future, these requirements should be satisfied with many star and galaxy names. The name VIRTTAC-Castor is chosen for the first aircraft of the VIRTTAC family introduced hereafter. This aircraft is a twin-turbofan configuration in the 100-passenger category. A twin-turboprop variant of this aircraft is foreseen and the name VIRTTAC-Pollux is already reserved for it.

\section{VIRTTAC-Castor Model}

\subsection{Aircraft Geometry and Configuration}

VIRTTAC-Castor represents a generic short- to medium-haul transport aircraft for around 100 passengers with a high wing (small anhedral) and a T-tail configuration. This configuration has been completely created from scratch for VIRTTAC. It has a configuration that remembers the Dornier 328 JET but is significantly larger. It is somewhat between a BAe 146200 / AVRO RJ85 and a BAe 146-300 / AVRO RJ100 in terms of size, but only has two turbofan engines. Note that, even if DLR did identify models for the Dornier 328 [26] the herein proposed model was not derived from these data. As already mentioned, this configuration will receive a sibling (VIRTTAC-Pollux) later that will be based on two turboprop engines, leading to different engine dynamic behavior as well as 
greater coupling of the engines and the aerodynamics due to the propeller slipstream.

An artistic illustration of the VIRTTAC-Castor is given in figure 1 and as well in figure 2 as three-side view. This illustration is provided for a common understanding of the modeled aircraft but no CAD model and precise geometry is given/distributed (at least for now). This aircraft was not produced through a complete pre-design process but its dimensions and characteristics should correspond to a short-to-medium range commercial air transportation role with a capacity of around 100 passengers. Table 1 provides an overview on its current dimensions and characteristics, which is not complete but can give the user the necessary information for subsequent model use.

\subsection{Aircraft Aerodynamics}

The aircraft model's aerodynamics contain formulations to consider nonlinear and unsteady effects of wing and empennage. The model benefits from DLR's large experience in modeling and identifying complex aerodynamic models for different airplanes, regions of the corresponding flight envelope and distinct applications in simulation [40, 41, 26]. The aerodynamic model is primarily formulated as a derivative model but includes several specific and complex extensions to enhance the model's capabilities. It allows for example to cover unsteady trailing edge flow separation, which allows to model the normal stall behavior for an aircraft configuration as given in figure 1 . The aerodynamic model formulation further allows to easily implement failure cases of an aerodynamic degradation of various sources as defined in section 2.7. A ground effect model (ground currently always at the elevation of 0 meters) is already included.

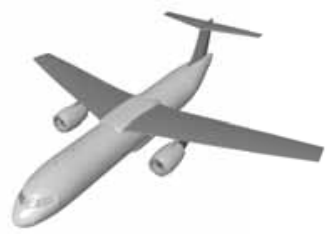

Figure 1: Artistic illustration of the VIRTTAC-Castor configuration.

\begin{tabular}{ll}
\hline AC length & $30.0 \mathrm{~m}$ \\
wing span & $28.0 \mathrm{~m}$ \\
horizontal tail span & $10.4 \mathrm{~m}$ \\
wing area & $75.0 \mathrm{~m}^{2}$ \\
horizontal tail area & $20.0 \mathrm{~m}^{2}$ \\
wing aspect ratio & 10.4 \\
mean aerodynamic chord & $2.17 \mathrm{~m}$ \\
\hline max. take-off weight & $56000 \mathrm{~kg}$ \\
empty weight & $33000 \mathrm{~kg}$ \\
max. fuel weight & $16000 \mathrm{~kg}$ \\
max. payload / PAX weight & $12000 \mathrm{~kg}$ \\
max. range & $5500 \mathrm{~km}$ \\
max. altitude & $35000 \mathrm{ft}$ \\
max. operating Mach number & 0.76 \\
cruise Mach number & 0.725 \\
\hline
\end{tabular}

Table 1: Overall dimensions and characteristics of VIRTTAC-Castor.

\subsection{Propulsion}

The VIRTTAC-Castor model includes two turbofan engine models which can be controlled separately. The engine command inputs virtually correspond to a N1 (engine fan shaft rotation speed) expressed in \%. The dynamic model will therefore correspond to the behavior of the engine plus the corresponding FADEC.

In the long-term quite good engine dynamic models will be integrated in VIRTTAC-Castor and in all or most models in the VIRTTAC family. However, a significant amount of work is still required from the authors in order to finish building up these models and to integrate them into the VIRTTAC structure. As a consequence, the first versions of VIRTTAC-Castor are expected to be delivered with much simpler preliminary models. These models will be representative for most scenarios, but as soon as the user-implemented flight control system will be very dependent on the engines' transient response, the validity of results will have to be checked. For instance, no serious development and tuning of a control law or autopilot based only on the engines (i.e. a propulsion-controlled aircraft or PCA as in $[42,43,44,45])$ will be possible with the preliminary model. Simple relatively low-gain autothrust/autothrottle functions would however not be too strongly affected. 


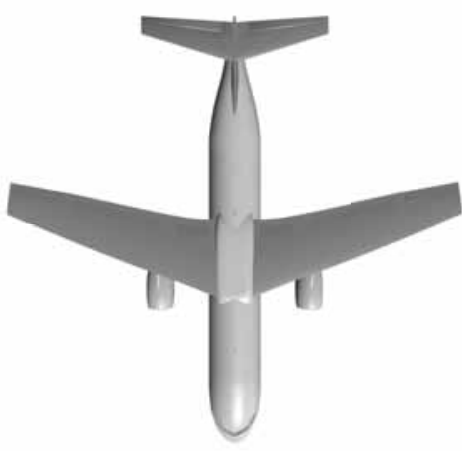

(a) top view

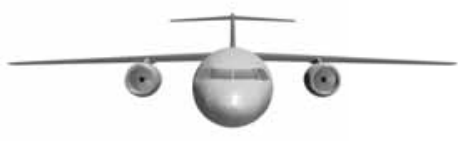

(b) front view

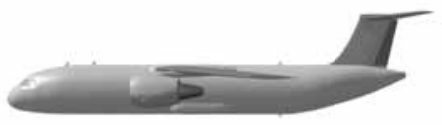

(c) side view

Figure 2: Artistic illustration of the VIRTTAC-Castor configuration, multiview projection.

\subsection{Flight Controls}

The simulation model of VIRTTAC-Castor contains several control surfaces including various spoilers on the wing which may be more than usual for this size of airplane. In detail, the model provides:

- trimable horizontal stabilizer

- left and right elevators

- left and right ailerons

- rudder

- five spoilers on each side (four roll spoilers/airbrakes and one ground spoiler)

Actuator models are included for all control surfaces. Limits (deflection, deflection rate, and acceleration) are included. The actual control surface deflection is measured internally by the actuator and provided as output of the VIRTTAC-Castor model. The com- manded signal and the measured deflection can therefore be compared; for instance users might want to compare them within a flight control system fault detection logic. Numerous possible faults will be integrated in the actuator models and be added over time, see section 2.7 hereafter.

\subsection{Sensor models}

Sensor models are a crucial element for VIRTTAC: they are the only way to know what is happening to the aircraft during the simulation. The physical quantities measured, the sensor characteristics (e.g. calibration, noise, dynamic behavior, quantization errors) as well as all the real-world issues related to where and how they are installed on the airframe will be defined as closely as possible to the state-of-the-art regular aircraft instrumentation. Currently, the authors are considering future inclusion of better sensors, which would resemble a complementary flight test instrumentation (FTI) and could be used for system identification studies. If FTIlike sensors were included in VIRTTAC in the future, these sensors should not be used for flight control, flight control adaptation, or fault detection and isolation studies as they would not normally be available on the aircraft in regular operations.

The usual list of measurements provided by air data and inertial reference systems on Part/CS-25 airplanes is available for VIRTTAC(-Castor). This includes attitude angles, rotational rates, accelerations, inertial velocity vector, static and total pressure and vertical speed, the various airspeeds, inflow angles $(\alpha, \beta)$, air temperature, etc. and many derived quantities. For each available measurement sensor characteristics and realworld effects are considered. When it is common practice to have redundancies in the regular aircraft instrumentation, several sensors will also be modeled. The relationships used in practice to derive the physical quantities that are not directly measured will be modeled such that the propagation of faulty measurements can be correctly simulated during faulty scenarios.

For now, VIRTTAC-Castor contains three inertial reference units providing the corresponding measurements of accelerations, rotational rates and attitude. Furthermore, there are four air data systems measuring angle of attack, angle of sideslip, and calibrated airspeed as well as static pressure, static temperature and barometric altitude ${ }^{1}$.

\footnotetext{
${ }^{1}$ with VIRTTAC-Castor version 0.5-alpha
} 


\subsection{Landing gear}

The influence of the landing gear on the aerodynamics is already included, but the gear itself, the wheel and tire dynamics as well as the braking system are not implemented yet. In the future, VIRTTAC will also include models for the landing gears and their systems as well as more realistic ground elevation profiles and runway characteristics.

\subsection{Test scenarios and failure cases}

For the first version of the benchmark model several test scenarios and failure cases are already available and will be extended in the future. The currently foreseen set of scenarios mainly contains aerodynamic degradation and control surface actuator failures:

\section{Wing Ice Case}

Ice can have hazardous effects on the aircraft's flight characteristics. Large accumulations on the wing mainly mostly near the wing leading edge - increase the drag and reduce the maximum angle of attack and consequently increase the stall speed. This has a direct influence on the safe flight envelope and poses a threat to crew and passengers. VIRTTAC-Castor (and probably most future VIRTTAC family models) will be capable of considering the effects of a generic wing ice accumulation in terms of the resulting aerodynamic degradation. The timely increase of degradation resp. accumulation as well as a de-icing can be triggered by the user whereas the details about the degradation itself are part of the closed model to allow a fair and realistic test of new developments like detection algorithms or robust flight controllers. The corresponding knowledge about the expectable effects and a realistic amount of degradation is derived from previous icing research at DLR [46, 47] where high-quality simulation models were identified from flight data.

\section{Horizontal Tail Damage \& Icing}

The model will include changes of dynamic behavior caused by a partial loss (various levels) of one side of the HTP similar to [48] resulting in a changed controllability of the aircraft. Partial damage at the HTP or VTP leading edge as well as local icing of the empennage will probably be included in the future.

\section{Actuator Faults}

Faults in the actuators will be included in the future. Each actuator will be controlled independently (ailerons, elevators, rudder, spoilers) and possibly be subject to faults. The faults cases that will be implemented include the typical actuator faults such as hardover, runaway, frozen at a given position, change in dynamic behavior, etc.

\section{Engine Bird Strike}

Bird strike damage to engines is considered for later inclusion in VIRTTAC-Castor. Simulation models were developed at DLR for the EU FP7 Man4Gen project $[49,50]$, which could be adapted for the VIRTTACCastor turbofan engine, once its nominal version will be available. These models are relatively simple and the variability of the effects of bird strikes in engines makes it very difficult, if not impossible, to build a generically valid model for such events. Investigating the adverse consequences of such failures onto advanced fault detection algorithms and their robustness against them is certainly interesting. This would be possible when such engine fault models will be integrated into VIRTTAC.

\section{Implementation Challenges}

\subsection{Need for a Black-Box implementation}

The internal implementation of the VIRTTAC dynamic models is hidden from the user (black-box), which permits to prevent users from accessing any information which would not be available in practice. In the MAT$\mathrm{LAB} /$ Simulink environment this is done by encapsulating the dynamic model in a Simulink s-function. This has also the advantage of significantly speeding-up the simulations while still letting the users be able to include their part (e.g. a flight control system) around the VIRTTAC flight mechanics models. At the time of writing this paper, the current implementation of the VIRTTAC-Castor model runs about 50 times faster than real-time on a Desktop PC with MATLAB/Simulink R2007b 32bit under Windows 7 Enterprise SP1 and with an Intel Core i7-2600@3.4 GHz. 


\subsection{Availability beyond MATLAB/Simulink}

The authors (and designers of VIRTTAC) also aim at ensuring the wide availability of the VIRTTAC models and their long-term maintainability. The wide availability includes the possibility to bring VIRTTAC to other environments, including other scientific software suites than MATLAB/Simulink. The internal implementation therefore makes a clear separation between the MATLAB/Simulink-specific features/APIs and the code responsible for the trim and simulation of the aircraft. The former is confined to the s-function code which is only a wrapper for the actual dynamic model (the latter). The latter is implemented in a library to which the s-function is statically linked. This decomposition should permit to create VIRTTAC implementations which could be used with a large variety of other tools, such as Scilab/Xcos or even using the Python programming language. The authors want to have the possibility of offering VIRTTAC for other tools than MAT$\mathrm{LAB} /$ Simulink with a reasonably low amount of work; however, it is crucial to ensure that the capabilities provided by VIRTTAC and its specific benchmarks remain the same for all these implementations. A benchmark scenario will only be officially supported by the authors if it is available for all supported implementations, or if there is a valid technical reason for not doing it. A valid technical reason might be that the benchmark scenario includes VIRTTAC and another component which cannot be ported to the other tools/platforms (e.g. due to intellectual property restrictions or if porting this component would require an unreasonable effort).

\subsection{Modularity for Long-Term maintainability}

The long-term maintainability includes the need for a modular internal structure of the simulation code. This is done by using a general structure, whereby the different model parts can be defined separately and "connected" to each other. This makes the modeling paradigm used inside the VIRTTAC models similar to the one used in graphical modeling tools, like Simulink or Xcos. No graphical editor has been developed to create or edit these connections but the $\mathrm{C}++$ syntax used for this is as simple as the MATLAB/Simulink "add_line" command. The internal implementation concept chosen might evolve over time without the VIRTTAC users noticing any change ${ }^{2}$. Currently, the

\footnotetext{
${ }^{2}$ Beyond possibly slightly modified rounding errors, which could also be caused by changing the compiler or the compiler flags.
}

internal implementation is a compromise between modularity and complexity of the implementation workflow. More automated or even code-generation-based solutions have not been chosen because it has been estimated that their additional level of complexity and their restrictions ${ }^{3}$ outweigh the benefit expected for VIRTTAC. Depending on the future evolution of VIRTTAC and of the corresponding aircraft models and benchmark scenarios this choice might be reevaluated. One of the important features that the current implementation requires is a mechanism permitting to call the different model parts in the right order such that the simulation results remain correct, i.e. as if the model had not been split into different entities. Note that such a mechanism is also required in simulation tools like Simulink and $\mathrm{Xcos}$.

The main modules that are currently defined are:

- Flight Control Actuators

- Propulsion

- Airframe Dynamics (which includes the aerodynamics and the equations of motion)

- Sensors

- Landing Gear (foreseen but not implemented yet).

A simple environment model is already included in the current version of VIRTTAC but is not a separate module. It includes a standard atmosphere model and a Dryden turbulence generator. The possibility to bring some icing conditions is currently being developed to enable icing-related envelope reduction benchmark scenarios. The implementation of the environment model is likely to be largely redesigned in the near to mid-term future.

\section{Conditions of Use}

\subsection{Who can use VIRTTAC? What are the conditions of use?}

\section{Source files}

As of now, anyone can download and use the VIRTTAC models. Any part of VIRTTAC provided in source form (e.g. MATLAB .m files or Simulink models) is subject to the very permissive MIT license:

\footnotetext{
${ }^{3}$ They always include some assumptions on the structure of the system and/or produce a barely human-readable code.
} 


\section{MIT License}

Copyright (c) 2018 Deutsches Zentrum für Luftund Raumfahrt e.V., Christoph Deiler, Nicolas Fezans

Permission is hereby granted, free of charge, to any person obtaining a copy of this software and associated documentation files (the "Software"), to deal in the Software without restriction, including without limitation the rights to use, copy, modify, merge, publish, distribute, sublicense, and/or sell copies of the Software, and to permit persons to whom the Software is furnished to do so, subject to the following conditions:

The above copyright notice and this permission notice shall be included in all copies or substantial portions of the Software.

THE SOFTWARE IS PROVIDED "AS IS", WITHOUT WARRANTY OF ANY KIND, EXPRESS OR IMPLIED, INCLUDING BUT NOT LIMITED TO THE WARRANTIES OF MERCHANTABILITY, FITNESS FOR A PARTICULAR PURPOSE AND NONINFRINGEMENT. IN NO EVENT SHALL THE AUTHORS OR COPYRIGHT HOLDERS BE LIABLE FOR ANY CLAIM, DAMAGES OR OTHER LIABILITY, WHETHER IN AN ACTION OF CONTRACT, TORT OR OTHERWISE, ARISING FROM, OUT OF OR IN CONNECTION WITH THE SOFTWARE OR THE USE OR OTHER DEALINGS IN THE SOFTWARE.
Other files: executable, binaries, binary data All non-disclosed code and data files (e.g. executable, dynamic/static libraries, binary files, etc.) are licensed under the Creative Common Attribution-NoDerivs 4.0 Generic license (CC-BY-ND 4.0). A human-readable summary is provided hereafter: please refer to the official license text for the legally binding text. Note that any attempt to disassemble the binary code, binary data, executable, or dynamic/static libraries provided is hereby considered as a derivative and is consequently hereby prohibited, even if not shared. A normal use of VIRTTAC for its intended purpose does not require such operations and therefore users will normally not be affected by this restriction.

CC-BY-ND 4.0 (human-readable summary)

\section{- You are free to:}

- Share - copy and redistribute the material in any medium or format for any purpose, even commercially.

- The licensor cannot revoke these freedoms as long as you follow the license terms.

\section{- Under the following terms:}

- Attribution - You must give appropriate credit, provide a link to the license, and indicate if changes were made. You may do so in any reasonable manner, but not in any way that suggests the licensor endorses you or your use.

- No Derivatives - If you remix, transform, or build upon the material, you may not distribute the modified material.

- No additional restrictions - You may not apply legal terms or technological measures that legally restrict others from doing anything the license permits. 


\section{Foreseen Applications and Community Involvement}

VIRTTAC is expected to become a very useful tool for a quite large community of researchers and engineers working in the areas of atmospheric flight mechanics (AFM) and guidance, navigation and control (GNC). A couple of foreseen uses are listed hereafter and the authors are welcoming further development suggestions linked to any other potential application of VIRTTAC.

\section{System Identification / Machine Learning}

Aircraft system identification is a rather obvious potential use of VIRTTAC, as it allows its users to perform virtual flight tests. Very few organizations and companies worldwide possess the financial resources and the technical means to perform large flight test campaigns for system identification purposes. VIRTTAC is expected to give many researchers and engineers access to a (virtual) test aircraft, who would not have this kind of possibility otherwise.

\section{Flight Control, Flight Guidance, and Fault- Tolerant Control}

The flight control and flight guidance communities can also benefit from VIRTTAC models as they constitute fully working and representative aircraft models on which control and guidance concept can be developed, tested, and compared among teams that would otherwise not have common benchmarks, for instance due to intellectual property restrictions. VIRTTAC is designed from the beginning to support fault-tolerant control in all its possible forms by providing representative models with many possible fault scenarios. The objective of the VIRTTAC models is to provide valid models 1) which help the users (e.g. control scientist) to understand the exact consequences of these faults on the overall system and 2) which can be used to validate and demonstrate the fault-tolerance capabilities of some controllers. Very often the fault-tolerant control techniques will require specific model formulations to be designed or to be used online: VIRTTAC provides no simplified model for control design, each user should build his/her own simplified model or reuse some that might have been built and shared by others.

Within a few years period, it is planned that VIRTTAC models will also be ported to the DLR AVES simulator in order to permit pilot-in-the-loop evaluations of the most interesting control concepts developed for
VIRTTAC and for which a pilot-in-the-loop evaluation could be valuable. Please contact the authors for further information on VIRTTAC@AVES or to send some suggestions.

\section{Teaching Flight Mechanics and Control}

The authors expect that VIRTTAC could become very useful for teaching purposes (in aerospace engineering but also for pilot training), even though teaching is not in the focus of the current developments. Nevertheless, the authors would be happy to support such efforts, within what can reasonably be performed without limiting the usability for the other potential user groups.

\section{Long Term Evolution of the Model and Com- munity Involvement}

The model provided with this paper is only the first step of a long-term initiative aiming at providing good and representative models to the community. Even if the task of building a flight dynamics model is a very instructive, the amount of work spend in our community to build models for the purpose of our research activities is very high. Additionally these models are often very restricted due to unavailability of the required data to the model builder or to other practical constraints. The multiplication of models and the relative lack of a common benchmark often makes it difficult to compare the proposed approaches.

The evolution of the herein proposed benchmark models and scenarios will be strongly oriented towards the needs of the community. In order to remain a good validation tool, the system will need to remain only partly observable to the end user and therefore some parts will remain undisclosed (at least for several years). For everything else (e.g. definition of new test scenarios, automatized evaluation scripts, etc.) VIRTTAC will be as open as possible and contributions from the community are very much welcome.

\section{Summary}

This paper presents the recently started development of a series of generic aircraft models gathered within the VIRTTAC family. These models will be available to the research community in the future, e.g. as highquality validation benchmark models or for testing new methodologies in the fields of robust control or reduced envelope protection. The first model of this family, the 100-passenger jet airplane VIRTTAC-Castor, already 
provides within its preliminary 0.5 -alpha version a basis including various necessary functions to simulate respectively virtually flight test the aircraft on the one hand. On the other hand, the aircraft might already been used for its foreseen purposes. After finishing the development of VIRTTAC-Castor in the near future, it will be followed by a turboprop version of similar size called VIRTTAC-Pollux.

\section{VIRTTAC download and contact information}

To provide the models of the VIRTTAC family to the community, a GitHub repository was created. This repository is located at

https://github.com/VIRTTAC/VIRTTAC

and will be updated if necessary due to new model developments of aircraft within the VIRTTAC family.

For any questions on VIRTTAC-Castor, the VIRTTAC family or for general support concerning the VIRTTAC simulation, please use the following VIRTTAC email address:

VIRTTAC@dlr.de.

\section{References}

[1] Lombaerts T, Looye G, Ellerbroek J, Rodriguez y Martin M. Design and Piloted Simulator Evaluation of Adaptive Safe Flight Envelope Protection Algorithm. Journal of Guidance, Control, and Dynamics. 2017; 40(8):1902-1924.

[2] Lombaerts T, Looye G, Chu P, Mulder JA. Pseudo Control Hedging and its Application for Safe Flight Envelope Protection. AIAA Guidance, Navigation, and Control Conference, Guidance, Navigation, and Control and Co-located Conferences, Paper No AIAA 2010-8280. Toronto, Ontario, Canada: American Institute of Aeronautics and Astronautics, Inc. (AIAA). 2010; .

[3] Tomlin C, Lygeros J, Sastry S. Aerodynamic Envelope Protection Using Hybrid Control. Proceedings of the American Control Conference. Philadelphia, Pennsylvania, USA: Institute of Electrical and Electronics Engineers (IEEE). 1998; .

[4] Shin HH, Lee SH, Kim Y, Kim ET, Sung KJ. Design of a Flight Envelope Protection System Using a Dynamic Trim Algorithm. International Journal of Aeronautical and Space Sciences. 2011;12(3):241-251.
[5] Well KH. Aircraft Control Laws for Envelope Protection. AIAA Guidance, Navigation, and Control Conference and Exhibit, Guidance, Navigation, and Control and Co-located Conferences, Paper No. AIAA 2006-6055. Keystone, Colorado, USA: American Institute of Aeronautics and Astronautics, Inc. (AIAA). 2006;

[6] Rafi M, Steck JE, Rokhsaz K. A Microburst Response and Recovery Scheme Using Advanced Flight Envelope Protection. AIAA Guidance, Navigation, and Control Conference, Guidance, Navigation, and Control and Co-located Conferences, Paper No. AIAA 2012-4444. Minneapolis, Minnesota, USA: American Institute of Aeronautics and Astronautics, Inc. (AIAA). 2012; .

[7] Wilson JM, Peters ME. Automatic flight envelope protection for light general aviation aircraft. 28th Digital Avionics Systems Conference. Institute of Electrical and Electronics Engineers (IEEE) and American Institute of Aeronautics and Astronautics, Inc. (AIAA). 2009;

[8] Hossain KN, Sharma V, Bragg MB, Voulgaris PG. Envelope Protection and Control Adaptation in Icing Encounters. 41st Aerospace Sciences Meeting and Exhibit, Aerospace Sciences Meetings, Paper No. AIAA 2003-25. Reno, Nevada, USA: American Institute of Aeronautics and Astronautics, Inc. (AIAA). 2003; .

[9] Gingras DR, Barnhart BP, Ranuado RJ, Ratvasky TP, Morelli EA. Envelope Protection for In-Flight Ice Contamination. 47th AIAA Aerospace Sciences Meeting, Paper No. AIAA 2009-1458. Orlando, Florida: American Institute of Aeronautics and Astronautics, Inc. (AIAA). 2009; .

[10] Tekles N, Holzapfel F, Xargay E, Choe R, Hovakimyan N, Gregory IM. Flight Envelope Protection for NASA's Transport Class Model. AIAA Guidance, Navigation, and Control Conference, AIAA SciTech Forum, Paper No. AIAA 2014-0269). National Harbor, Maryland, USA: American Institute of Aeronautics and Astronautics, Inc. (AIAA). 2014; .

[11] Ackerman KA, Talleur DA, Carbonari RS, Xargay E, Seefeldt BD, Kirlik A, Hovakimyan N, Trujillo AC. Automation Situation Awareness Display for a Flight. Journal of Guidance, Control, and Dynamics. 2017; 40(4):964-980.

[12] Tekles N, Chongvisal J, Xargay E, Choe R, Talleur DA, Hovakimyan N, Belcastro CM. Design of a Flight Envelope Protection System for NASA's Transport Class Model. Journal of Guidance, Control, and Dynamics. 2017;40(4):863-877.

[13] Tang L, Roemer M, Ge J, Crassidis A, Prasad J, Belcastro C. Methodologies for Adaptive Flight 
Envelope Estimation and Protection. AIAA Guidance, Navigation, and Control Conference, Guidance, Navigation, and Control and Co-located Conferences, Paper No. AIAA 2009-6260. Chicago, Illinois, USA: American Institute of Aeronautics and Astronautics, Inc. (AIAA). 2009; .

[14] Gingras D, Barnhart B, Ranaudo R, Martos B, Ratvasky T, Morelli E. Development and Implementation of a Model-Driven Envelope Protection System for In-Flight Ice Contamination. AIAA Guidance, Navigation, and Control Conference, Guidance, Navigation, and Control and Co-located Conferences, Paper No. AIAA 2010-8141. American Institute of Aeronautics and Astronautics, Inc. (AIAA). 2010; .

[15] Falkena W, Borst C, Chu Q, Mulder J. Investigation of Practical Flight Envelope Protection Systems for Small Aircraft. Journal of Guidance, Control, and Dynamics. 2011;34(2):976-988.

[16] Ye H, Chen M, Wu Q. Flight Envelope Protection Control Based on Reference Governor Method in High Angle of Attack Maneuver. Mathematical Problems in Engineering. 2015;2015, Article ID 254975:15.

[17] Lambregts AA. Flight Envelope Protection for Automatic and Augmented Manual Control. Proceedings of the EuroGNC 2013, 2nd CEAS Specialist Conference on Guidance, Navigation \& Control. Delft, Netherlands: Council of European Aerospace Societies (CEAS). 2013; pp. 1364-1383.

[18] Hueschen RM. Development of the Transport Class Model (TCM) Aircraft Simulation From a Sub-Scale Generic Transport Model (GTM) Simulation. Technical Memorandum, National Aeronautics and Space Administration, Hampton, Virginia, USA. 2011. URL http: //hdl.handle.net/2060/20110014509

[19] Frink NT, Pirzadeh SZ, Atkins HL, Viken SA, Morrison JH. CFD assessment of aerodynamic degradation of a subsonic transport due to airframe damage. In: Proceedings of the 2010 AIAA Aerospace Science Meeting, AIAA 2010-500. Orlando, FL, USA: American Institute of Aeronautics and Astronautics, Inc. (AIAA). 2010; .

[20] Klein V. Aircraft parameter estimation in frequency domain. 4th Atmospheric Flight Mechanics Conference, Guidance, Navigation, and Control and Co-located Conferences, Paper No. AIAA 1978-1344. Palo Alto, CA, U.S.A.: American Institute of Aeronautics and Astronautics, Inc. (AIAA). 1978; .

[21] Morelli EA, Klein V. Optimal input design for aircraft parameter estimation using dynamic programming principles. 17th Atmospheric Flight Mechanics Conference, Guidance, Navigation, and Control and Co-located Conferences, Paper No. AIAA-90-2801. Portland, Oregon, USA. 1990; .

[22] Lichota P, Sibilski K, Ohme P. D-Optimal Simultaneous Multistep Excitations for Aircraft Parameter Estimation. Journal of Aircraft. 2017;54(2):747-758.

[23] Raol J, Jategaonkar RV. Aircraft parameter estimation using recurrent neural networks - A critical appraisal. 20th Atmospheric Flight Mechanics Conference, Guidance, Navigation, and Control and Co-located Conferences, Paper No. AIAA-95-3504. Baltimore, Maryland, USA: American Institute of Aeronautics and Astronautics, Inc. (AIAA). 1995;

[24] Jategaonkar RV, Thielecke F. Aircraft parameter estimation - A tool for development of aerodynamic databases. Sadhana. 2000;25:119-135.

[25] Jategaonkar RV, Plaetschke E. Algorithms for Aircraft Parameter Estimation Accounting for Process and Measurement Noise. Journal of Aircraft. 1989; 26(4):360-372.

[26] Jategaonkar R, Fischenberg D, von Gruenhagen W. Aerodynamic Modeling and System Identification from Flight Data-Recent Applications at DLR. Journal of Aircraft. 2004;41(4):681-691.

[27] Iliff KW. Aircraft parameter estimation. 25th AIAA Aerospace Sciences Meeting, Paper No. AIAA 1987-0623. Reno, Nevada, USA: American Institute of Aeronautics and Astronautics, Inc. (AIAA). 1987; .

[28] Chandler PR, Pachter M, Mears M. System Identification for Adaptive and Reconfigurable Control. Journal of Guidance, Control, and Dynamics. 1995; 18(3):516-524.

[29] Morelli EA. In-flight system identification. 23rd Atmospheric Flight Mechanics Conference, Guidance, Navigation, and Control and Co-located Conferences, Paper No. AIAA-98-4261. Boston, MA, USA: American Institute of Aeronautics and Astronautics, Inc. (AIAA). 1998;

[30] Morelli EA. Practical Aspects of the Equation-Error Method for Aircraft Parameter Estimation. AIAA Atmospheric Flight Mechanics Conference and Exhibit, Guidance, Navigation, and Control and Co-located Conferences, Paper No. AIAA 2006-6144. Keystone, Colorado,USA: American Institute of Aeronautics and Astronautics, Inc. (AIAA). 2006; .

[31] Peyada NK, Ghosh AK. Aircraft parameter estimation using a new filtering technique based upon a neural network and Gauss-Newton method. The Aeronautical Journal. 2009;113(1142):243-252. 
[32] Peyada N, Ghosh A. Aircraft Parameter Estimation Using Neural Network Based Algorithm. AIAA Atmospheric Flight Mechanics Conference, Guidance, Navigation, and Control and Co-located Conferences, Paper No. AIAA 2009-5941. Chicago, IL, USA: American Institute of Aeronautics and Astronautics, Inc. (AIAA). 2009; .

[33] Chowdhary G, Jategaonkar R. Aerodynamic parameter estimation from flight data applying extended and unscented Kalman filter. Aerospace Science and Technology. 2010;14(2):106-117.

[34] Morelli EA. Flight Test Maneuvers for Efficient Aerodynamic Modeling. Journal of Aircraft. 2012; 49(6):1857-1867.

[35] Morelli EA, Klein V. Application of System Identification to Aircraft at NASA Langley Research Center. Journal of Aircraft. 2005;42(1):12-25.

[36] Dorobantu A, Murch A, Mettler B, Balas G. System Identification for Small, Low-Cost, Fixed-Wing Unmanned Aircraft. Journal of Aircraft. 2013; 50(4):1117-1130.

[37] Fujimori A, Ljung L. A polytopic modeling of aircraft by using system identification. International Conference on Control and Automation. Budapest, Hungary: Institute of Electrical and Electronics Engineers (IEEE). 2005;

[38] Fujimori A, Ljung L. Model identification of linear parameter varying aircraft systems. Journal of Aerospace Engineering. 2006;220(4):337-346.

[39] Jategaonkar RV. Flight Vehicle System Identification: A Time-Domain Methodology, Second Edition. Progress in Astronautics and Aeronautics. American Institute of Aeronautics and Astronautics, Inc. 2015. ISBN: 978-1-62410-278-3. eISBN: 978-1-62410-279-0. URL https: / /doi .org/10.2514/4.102790

[40] Fischenberg D. Identification of an unsteady aerodynamic stall model from flight test data. No. AIAA 95-3438-CP in AIAA Atmospheric Flight Mechanics Conference. Baltimore, Maryland, USA: American Institute of Aeronautics and Astronautics, Inc. (AIAA). 1995; pp. 138-146.

[41] Fischenberg D, Jategaonkar RV. Identification of Aircraft Stall Behavior from Flight Test Data. No. 17 in RTO Systems Concepts and Integration Panel (SCI) Symposium: System Identification for Integrated Aircraft Development and Flight Testing. Madrid, Spain: NATO Research and Technology Organisation. 1998; .

[42] Burcham FWJ, Burken JJ, Maine TA, Fullerton CG. Development and flight test of an emergency flight control system using only engine thrust on an MD-11 transport airplane. Tech. rep., NASA. 1997. TP-97-206217.

[43] Bull J, Mah R, Hardy G, Sullivan B, Jones J, Williams D, Soukup P, Winters J. Piloted simulation tests of propulsion control as backup to loss of primary flight control for a B747-400 jet transport. Tech. rep., NASA. 1997. TM-112191.

[44] Fezans N. Simple control law structure for the control of airplanes by means of their engines. In: Advances in Aerospace Guidance, Navigation and Control, edited by Holzapfel F, Theil S. Springer. 2011;ISBN: 978-3-642-19816-8.

[45] Fezans N, Gamaleri M. Emergency propulsion-based autoland system. In: Proceedings of the ICAS Congress 2012. Brisbane, Australia. 2012; .

URL http: / /www.icas.org/ICAS_ARCHIVE/ ICAS2012/ABSTRACTS/503.HTM

[46] Deiler C. Time Domain Output Error System Identification of Iced Aircraft Aerodynamics. CEAS Aeronautical Journal. 2017;8(2):231-244.

[47] Deiler C. Aerodynamic Modeling, System Identification, and Analysis of Iced Aircraft Configurations. Journal of Aircraft. 2018; 55(1):145-161.

[48] Fezans N, Kappenberger C. A model of horizontal tailplane damage for use in flight dynamics. 28th International Congress of the Aeronautical Sciences. Brisbane, AUS: International Council of the Aeronautical Sciences (ICAS). 2012; p. 14. URL http: //www.icas.org/ICAS_ARCHIVE/ ICAS2012/PAPERS/508.PDF

[49] Buch JP, Niedermeier D. Das Man4Gen-Projekt: Unterstützung von Airline-Crews in unerwarteten Situationen. In: Proceedings of the 2016 German Aerospace Congress (DLRK). Braunschweig, Germany. 2016; .

[50] Buch JP, Niedermeier D, Stepniczka I. Managing the Unexpected. AIAA Modeling and Simulation Technologies (MST) Conference, AIAA AVIATION Forum, AIAA 2017-4155. Denver, CO, USA: American Institute of Aeronautics and Astronautics, Inc. (AIAA). 2017; 